\title{
Três teses sobre a verdade na Doutrina-Da-Ciência
} De 1804

\section{Thiago Santoro}

\section{(2) OpenEdition}

Journals

Edição electrónica

URL: http://journals.openedition.org/ref/355

DOI: $10.4000 /$ ref.355

ISSN: 2258-014X

Editora

EuroPhilosophie Editions

Refêrencia eletrónica

Thiago Santoro, «Três teses sobre a verdade na Doutrina-Da-Ciência De 1804 », Revista de Estud(i)os sobre Fichte [Online], 2 | 2011, posto online no dia 22 novembro 2011, consultado o 08 setembro 2020. URL : http://journals.openedition.org/ref/355 ; DOI : https://doi.org/10.4000/ref.355

Este documento foi criado de forma automática no dia 8 setembro 2020

(C) EuroPhilosophie 


\title{
Três teses sobre a verdade na Doutrina-Da-Ciência De 1804
}

\author{
Thiago Santoro
}

\section{Unidade absoluta do saber: sobre idealismo e realismo}

1 A primeira tese, emblema do projeto de filosofia sistemática comum a toda tradição do Idealismo Alemão e desde cedo defendida por Fichte ${ }^{1}$, aparece de modo claro já no início do texto de 1804: "existe a verdade, a qual é unicamente verdadeira, e tudo aquilo fora dela incondicionalmente falso; e essa verdade pode de fato ser encontrada e se evidencia imediatamente como pura e simplesmente verdadeira". (WL18042 GA II/8, 4/ FSW X, 90) ${ }^{2}$ A defesa da tese sobre a unidade absoluta do saber, que de acordo com Fichte consta como objetivo final de qualquer investigação filosófica genuína, estabelece um monismo lógico que equipara o conceito de verdade à ideia da superação completa de todas dicotomias ou de todo dualismo. A razão só poderá conquistar plena autonomia, e portanto uma verdadeira autofundamentação, quando atingir esse grau máximo de universalidade, e conseguir com isto extirpar qualquer possibilidade de contradição interna à sua estrutura sistemática. Caso contrário, como nos diz Fichte,

“onde quer que surja qualquer possibilidade evidente ou tácita de diferenciação, a tarefa ainda não foi resolvida. Alguém que possa demonstrar alguma distinção possível naquilo que um sistema filosófico postula como o mais elevado, esse refutou o mesmo sistema." (WL1804² GA II/8, 8/FSW X, 93)

Mas o que exatamente significa essa absoluta unidade do saber para Fichte? Como o filósofo compreende essa estrutura sistemática necessária e ao mesmo tempo unívoca de todo conhecimento humano? O esclarecimento de Fichte aponta para a mútua implicação entre fundamento e fundado, afirmação que em certo sentido antecipa aqui a compreensão hegeliana de sistema, mas com uma pequena e importante ressalva: tal relação se estabelece no "intuicionar contínuo do próprio filósofo", como indica a continuação do texto fichtiano:

“absoluta unidade [...], o puro fechado em si mesmo, o verdadeiro, imutável em si.

Reconduzir: justamente no intuicionar ${ }^{3}$ contínuo do próprio filósofo, e portanto: 
que ele conceba o múltiplo através do uno, e o uno através do múltiplo, i.e., que para ele a unidade $=$ A se evidencie como princípio dessa multiplicidade; e viceversa, que a multiplicidade segundo o fundamento de seu ser só possa ser concebida como principiado de A." (Ibidem)

3 A bem dizer, essa definição da unidade absoluta, de cunho platônico, ao simplesmente determinar de modo completamente abstrato um necessário vínculo entre o uno e o múltiplo, ainda não revela o que propriamente se pode tomar por múltiplo ou uno, não concede ainda nenhuma determinação desses termos. Tampouco é esclarecido acima qual o papel do intuicionar do filósofo nessa conjunção. De fato, a ressalva antes destacada é fundamental. $\mathrm{O}$ intuicionar ou insight do filósofo não é aqui apenas uma observação marginal de Fichte, ou simplesmente indicação de que se está pensando sobre a relação em questão, mas se mostra como elemento constitutivo da própria unidade investigada.

Entretanto, na continuação da explanação fichtiana, encontra-se uma passagem bastante propensa à interpretação equivocada. De certo modo, esse texto que já aparece logo no início da Doutrina-da-Ciência de 1804, a meu ver, pode ser tomado como uma das fontes de um erro de interpretação disseminado em grande parte da literatura específica sobre esse Opus magnum de Fichte. Na busca da unidade suprema do saber, o autor retoma aqui a distinção entre ser e consciência, contraposição essa característica da teoria geral da representação, para em seguida indicar que não é possível estabelecer tal unidade absoluta do saber a partir de qualquer dos dois termos:

"cada um pode [...] notar que todo ser postula um pensamento ou uma consciência desse ser; que portanto o puro ser é sempre apenas uma metade em relação à outra, ao pensamento desse ser, e conforme a isso é membro de uma disjunção originária e mais elevada [...] Assim, a absoluta unidade não pode ser posta nem no ser, nem na consciência que está contraposta a ele; não será posta na coisa, e tampouco na representação da coisa; mas sim no princípio, recém revelado por nós, da absoluta unidade e inseparabilidade de ambas, o qual simultaneamente, como vimos também, é princípio da disjunção de ambas; princípio que gostaríamos de denominar puro saber, saber em si." (WL1804² GA II/8, 12-14/FSW X, 95-6)

5 Uma rápida leitura ipsis litteris dessa passagem do texto sem dúvida parece conduzir à seguinte interpretação: ora, se a absoluta unidade não é nem a coisa (isto é, o ser, a objetividade), nem a consciência (o sujeito), como claramente afirma Fichte (e como queria Hegel), então tal unidade só pode ser encontrada na superação de ambos os opostos, em um saber absoluto. Até aqui, tal interpretação segue à risca o texto do autor. O problema reside no modo como essa superação é concebida, e especialmente na forma de interpretar os termos da relação. Explico: na medida em que Fichte fala de uma contraposição entre ser e consciência, e sobre a superação dessa dicotomia por um saber absoluto, o termo 'consciência' é imediatamente equiparado à própria subjetividade como um todo, e o argumento de Fichte parece indicar assim uma verdadeira Kehre da postura idealista transcendental, pois dito saber absoluto aparentemente se mostra por completo desvinculado de qualquer elemento subjetivo. ${ }^{4}$ Eis, portanto, como alguns intérpretes transformaram a epistemologia transcendental de Fichte na contraditória ideia de uma ontologia do saber absoluto. ${ }^{5}$

Contudo, o conceito de consciência da passagem supracitada é ali empregado por Fichte justamente enquanto sinônimo de consciência intencional, ou, mais precisamente, "representação da coisa" e "pensamento desse ser", uma consciência em oposição ao objeto ou ser visado. 0 parágrafo em questão faz uma descrição da duplicidade inerente à consciência representacional, e com razão indica que essa configuração da 
consciência não pode constar como princípio de unidade do saber. Assim, o princípio "recém revelado por nós", denominado por "saber absoluto", não designa uma recusa de toda e qualquer instância subjetiva, mas simplesmente recusa a identificação do idealismo transcendental a um subjetivismo naïve $e^{6}$, ao mesmo tempo em que não aceita a possibilidade de uma fundamentação ontológica do conhecimento no "puro ser". 0 monismo teórico de Fichte assume, consequentemente, a tarefa de demonstrar essa unidade última de toda disjunção como inerente ao próprio saber.

7 Se a unidade do conhecimento deve unificar os dois elementos daquilo que Hölderlin denominou "partição original" que se mostra como estrutura mais geral da relação cognitiva da consciência intencional com o mundo, tal disjunção unifica por sua vez o múltiplo caracterizado pela dúplice determinação kantiana da experiência humana. Assim, na linguagem esquemática de Fichte, a unidade absoluta entre ser e pensar (A = D/S, cf. WL1804 GA II/8, 24-26/FSW X, 102 $)$ é também unidade entre a experiência sensível, o mundo moral, e a união entre ambos: x, y, z. (cf. WL1804² GA II/8, 26/FSW X, 103) Nesse sentido, a unidade do saber almejada pela doutrina-da-ciência é em certo sentido uma unificação dos aspectos real e ideal da experiência da consciência, ou seja, busca-se aqui um verdadeiro ideal-realismo fundado na atividade cognitiva enquanto tal.

Entretanto, mesmo que o objetivo geral das lições de 1804, em última instância, esteja de acordo com a interpretação aqui sugerida, isto é, considerando que a teoria desenvolvida por Fichte permaneça de fato concordante com a proposta de um sistema transcendental-idealista fundamentado de modo absolutamente imanente, o texto fichtiano parece apresentar em alguns pontos certas inconsistências notáveis. Não se entende, por exemplo, como Fichte pode falar a respeito do saber ou da certeza como sendo uma "pura substância existente para si", (WL1804² GA II/8, 36/FSW X, 106) ou ainda, bem mais adiante no texto, como o autor pode se referir a uma "pura luz ou pura razão em si", cuja determinação se dá aparentemente "sem nenhuma intervenção possível nossa." (WL1804² GA II/8, 276/fsw X, 233) A partir dessas afirmações contextualmente problemáticas, compreende-se perfeitamente por que muitos comentadores dessa obra lêem-na a partir de um prisma ontológico.

É possível mostrar que tais discrepâncias constituem muito mais simples inconsistências no uso de determinados termos do que uma mudança radical na orientação geral da filosofia de Fichte. Isso fica mais claro, por exemplo, quando se observa, na continuação da página 106 do texto em questão, a explicação que Fichte oferece para aquele "saber enquanto um existente para si": "não conheceis vós então em todas essas determinações, e não é vosso saber, enquanto saber, sob todas as distinções dos objetos o mesmo saber idêntico a si próprio?" (WL1804² GA II/8, 36/FSW X, 106) Nesse sentido, o saber se mostra como instância que permanece subjacente a todas determinações predicativas do entendimento, como indica Fichte através da iteração infinita da continua relação entre ser e pensar dentro do próprio saber. (Cf. WL1804 ${ }^{2} \mathrm{GA}$ II/8, 38-40/FSW X, 108-9) ${ }^{9}$ O comentário de Stolzenberg deixa bem claro esse ponto:

“O puro saber não é algo como o saber a priori no sentido de Kant, um saber, portanto, que opera a partir de conceitos, cujo conteúdo não pode ser deduzido da experiência; o puro saber, para Fichte, é muito mais uma circunstância epistêmica, a qual é considerada quando a referência intencional a objetos, dos quais algo é sabido, é colocada por assim dizer em epoché, e somente a forma fundamental invariante do saber enquanto tal, para todos os casos de saber, é trazida à tona." (2006, p. 3). 
10 Importante notar aqui que o princípio uno subjacente à multiplicidade das determinações do entendimento não é compreendido por Fichte como uma unidade inerte e alheia à própria multiplicidade, e por isso mesmo não pode ser compreendido como substância. Por conseguinte, afirmar tal unidade do saber enquanto algo simplesmente fixo e imutável seria justamente recair no erro da objetificação da atividade do saber, transformando este saber em mero ser. Pelo contrário, a doutrinada-ciência busca um fundamento dinâmico de unidade, que contenha em si mesmo também o princípio de toda disjunção. Assim, o fundamento último do conhecimento jamais poderá identificar-se com uma unidade mística indiferenciada, a qual é na verdade produto de uma abstração vazia, mas mantém seu estatuto transicional, oscilando entre ambos os polos de qualquer manifestação determinada. Como indica o seguinte trecho da sexta lição do curso de 1804:

\begin{abstract}
“a verdadeira e correta unidade só pode ser o princípio ao mesmo tempo da unidade manifesta e da disjunção manifesta; e certamente não apenas como exterior, de modo que projetasse ambos, a unidade e o princípio de disjunção, expelindo objetivamente a manifestação, mas interior e orgânico; de modo que não pudesse ser princípio da unidade sem ser também a um só tempo princípio da disjunção, e viceversa." (WL1804² GA II/8, 86/FSW X, 132-3)
\end{abstract}

Essa descrição abstrata do conceito de uma unidade dinâmica entre opostos, ou melhor, de uma unidade que contém em si a própria dualidade - sem dúvida já presente no uso fichtiano do conceito de imaginação, no contexto da Grundlage - precisa, no entanto, ser comprovada a partir da própria construção efetiva do saber. Nesse sentido, um ponto de partida para o desenvolvimento dessa argumentação se encontra na contraposição entre as posições do idealismo e do realismo. Se há de fato uma unidade última do saber, tal unidade precisa coadunar essas duas perspectivas, que, de acordo com Fichte, esgotam os possíveis pontos de vista epistêmicos. Importante observar aqui que a análise de Fichte parte não de uma crítica específica a sistemas filosóficos que sustentam tais posições, mas seu ponto de partida, como afirma o próprio autor, é o idealismo e o realismo "natural, que se dá no conhecimento comum sem qualquer intervenção consciente nossa, ao menos em suas exteriorizações e manifestações derivadas". (WL1804² GA II/8, 178/FSW X, 180)10

12 Assim, a análise fichtiana inicia a partir de uma definição da postura idealista comum, que se revela como meramente fática. Mesmo que o texto abaixo mencione como exemplo dessa determinação fática o princípio da filosofia kantiana, será preciso investigar até ponto Fichte, ao falar de um "pôr de si mesmo" enquanto justificação absoluta do próprio idealismo, não está também realizando uma espécie de autocrítica ao desenvolvimento anterior de sua obra. Eis o trecho em questão:

"o modo de pensar idealista se coloca, através de seu próprio ser, na posição da reflexão, transforma essa posição absolutamente através de si própria em um absoluto, e seu desenvolvimento posterior não é nada além da gênese daquilo que já existia sem qualquer outra gênese, exceto sua própria gênese absoluta. Ele era portanto, em sua raiz, fático, não por estar em relação com algo outro fora dele (ex. a proposição suprema de Kant), mas em relação a si mesmo. Ele se põe pura e simplesmente, e todo o resto deve partir disso; e para além desse absoluto pôr de si mesmo ele dispensa outra justificação." (WL1804² GA II/8, 178-80/FSW X, 180-1)

13 Com essa definição, Fichte pretende destacar uma forma de idealismo unilateral e completamente fechado em si mesmo, cuja simples afirmação de si, enquanto axioma indiscutível, não possibilita um conhecimento de seu próprio fundamento. Em outras palavras, a postura do idealismo comum parte de um princípio dado como certo, e 
constrói a partir desse eixo inquestionável sua explicação da experiência. Assim, dizer que seu fundamento ou princípio é meramente fático significa mostrar que sua construção epistêmica não é uma verdadeira autoconstrução, indicando com isto que tal idealismo não investiga criticamente seu próprio princípio, ou, para utilizar a linguagem de Fichte, não se torna verdadeiramente genético. Destarte, inclusive a teoria transcendental sobre a construção dos objetos do conhecimento a partir da espontaneidade do entendimento pode incorrer no erro do dogmatismo metafísico, se pretende postular como fundamento último dessa estrutura transcendental espontânea um mero fato da razão, uma premissa que deve ser simplesmente aceita porque não pode ser comprovada, isto é, geneticamente reconstruída. Nesse sentido, essa forma dogmática de idealismo reproduz tal qual o "modo de pensar" objetificador do realismo, como indica claramente a seguinte passagem do texto da Doutrina-da-Ciência de 1804:

"em nada difere o proceder do modo de pensar realista. Ele pressupõe, com total abstração da facticidade de seu pensar, o puro conteúdo do mesmo, como unicamente válido e pura e simplesmente verdadeiro, negando assim de modo consequente toda outra verdade que não esteja ali contida, ou, como será de fato o caso aqui, que o contradiga." (WL1804² GA II/8, 180/FSW X, 181)

De acordo com essa análise, nenhuma das duas posições é capaz de estabelecer a unidade última do saber, pois cada qual mantém como absoluto apenas um dos dois polos constitutivos de qualquer objeto: forma e conteúdo. (Cf. Ibid.) ${ }^{11}$. Além disso, ambas as posições, ao determinarem entre si duas esferas do discurso que se negam reciprocamente, apresentam-se como completamente incomensuráveis; nenhuma é capaz de refutar a outra, pois não há entre elas uma base ou fundamento em comum. (Cf. WL18042 GA II/8, 182/FSW X, 182) Se, na tentativa de explicar o conhecimento, o idealismo comum afirma que só existe aquilo que é construído pelo sujeito, e, por outro lado, o realismo comum afirma que todo conhecimento provém de uma análise da própria coisa, cada uma dessas posições pode ser compreendida como uma abstração da outra.

15 Neste primeiro sentido, o idealista transcendental não encontra dificuldade para mostrar a inconsistência do realismo comum. Ele simplesmente revela, a partir da própria afirmação do realista, aquilo que tal afirmação deve inevitavelmente pressupor: o em-si se mostra como o pensar sobre o em-si. Assim, o realismo, tal como aquele cético criticado por Aristóteles ${ }^{12}$, se autorefuta tão logo pronuncia sua tese. Eis como Fichte, em um diálogo fictício com seus adversários, expressa esse ponto: "portanto, vosso intuicionar da aniquilação do pensamento no em-si pressupõe contudo o pensamento positivo; e a proposição assim se coloca: no pensamento, o pensamento aniquila a si próprio face ao em-si." (WL1804² GA II/8, 184/FSW X, 184) A ideia por trás dessa refutação consiste em demonstrar que toda suposta pura objetividade se revela como produto ou resultado de uma abstração, que ao mesmo tempo oculta o sujeito que abstrai esse em-si. Em outras palavras, toda afirmação de uma verdade exclusivamente objetiva é, no fundo, uma projeção da própria consciência, que não toma em consideração o próprio ato de projetar.

16 Mas o que é propriamente o em-si? Aqui surge o segundo e mais profundo sentido da posição realista. "O em-si deve ser descrito apenas como o aniquilador do pensamento." (WL1804² GA II/8, 182/FSW X, 183) Em outras palavras, o em-si afirmado pelo realismo é pretensamente uma instância por completo independente "do meu dizer e pensar, e de 
todo dizer e pensar e intuir", (WL1804² GA II/8, 182/FSW X, 183) uma pura alteridade da razão, tal como o foram para Kant os noumena.

Para Fichte, a afirmação de um puro em-si representa de certo modo uma reivindicação legítima do realismo, na medida em que o sistema de determinações conceituais da razão não consegue por si só encontrar um fundamento seguro de sua própria existência. Se o conceito realiza apenas uma constante transição entre determinações, se ele é por isso mesmo um vacilante Através (Durch, cf. WL1804² GA II/8, 26 ss./FSW X, 102 ss. $^{13}$ ), como neologismou Fichte, sua própria forma revela uma inerente limitação, bem como a necessidade de postular um princípio de existência que transcende o conceito. Por isso, como comenta Ingeborg Schüssler, "para a existência do Através é necessário uma vida absoluta em si, não contida nesse Através, fundamentada em si mesma". ${ }^{14}$ Mais do que isso, trata-se aqui, de acordo com a análise de Stolzenberg, do "significado positivo do conceito de em-si"15, que denota uma absoluta ausência de qualquer relação intra-epistêmica, e neste caso inclusive a ausência da própria relação negativa à construção conceitual postulada pelo idealismo. Se o conceito de em-si representa uma instância, ou melhor, a instância absolutamente autônoma e independente enquanto tal, ele jamais pode ser determinado por contraposição à sua pretensa negação, não pode "ser relata de uma relação"16.

No entanto, justamente por causa dessa clausura absoluta assumida também pelo realismo superior, sua posição acaba se tornando idêntica àquela do idealismo radical. Assim, não parece haver diferença significativa entre a afirmação da total autonomia e independência da razão e a mesma afirmação em relação a algo como uma não-razão, um puro em-si. Além disso, dita clausura absoluta impede que ocorra uma manifestação dessa unidade, ou dito de outro modo, o puro em si, seja ele um saber em si ou uma coisa em si, não contém qualquer determinação, e nesse sentido se torna uma totalidade indiferenciada que é ao mesmo tempo uma total nulidade; uma "noite onde todos os gatos são pardos"17.

Como então é possível resolver esse impasse, a partir de qual critério se poderá recuperar um ponto de apoio seguro para a unidade absoluta do saber? A meu ver, a única resposta satisfatória de Fichte para o problema em questão reside no conceito de imagem, ou, mais precisamente, no conceito de eu ou saber enquanto imagem. "Imagem, enquanto imagem, é o nervus probandi." (WL1804² GA II/8, 372/FSW X, 286) Mesmo sem entrar em detalhes nessa análise, pois pretendo discutir esse ponto mais adiante, observo o seguinte: se a unidade absoluta deve ser absolutamente autônoma, fechada em si mesma, tal como o conceito do puro em-si, e ao mesmo tempo deve ser algo de fato existente, manifesto, tal como articula a construção do saber, então a única forma de unificar ambas as exigências é através de uma instância cuja essência contenha seu próprio manifestar. Em outras palavras, o saber é absoluta unidade do conhecimento porque revela-se como saber, e só é como saber na medida em que sabe de si. Ou, para colocar de modo sucinto: o saber é porque sabe de si, e só sabe de si porque é. ${ }^{18}$ Isso talvez o que se possa depreender da seguinte passagem críptica do texto de Fichte:

"nem na reconstrução enquanto tal (da representação), nem no originário (na coisa-para-si), mas absolutamente em um ponto de vista entre ambos encontra-se o saber: ele reside na imagem da reconstrução, enquanto imagem, em cuja imagem surge para ele, através de uma lei interna, o pôr de uma lei. Isso, este transpassar [Durchdringen] da essência da imagem é a originária, absoluta e imutável unidade;" (WL1804² GA II/8, 372/FSW X, 287) 
A partir dessa constatação, de que a unidade absoluta do conhecimento, para além da distinção entre realismo e idealismo, deve se estabelecer como absolutamente imanente ao próprio saber (o que não significa dizer que ela seja absolutamente imanente ao conceito, como será discutido na próxima seção), permanece ainda a tarefa de explicar como essa imanência do saber pode ser compreendida enquanto manifestação da consciência, isto é, em que medida a unidade do saber absoluto se revela como o próprio eu. Um primeiro passo nessa direção consiste em explicitar uma segunda e mais profunda contraposição interna ao saber, sem dúvida decorrente daquela entre as duas posições epistêmicas antes analisadas: a contraposição entre intuição e conceito, considerada a partir de sua gênese na própria consciência. Segue sem mais a discussão sobre esse problema.

\section{Gênese da verdade na consciência: sobre conceito e intuição}

Intuição e conceito têm para a teoria transcendental kantiana significados bem delimitados: "por intermédio, pois, da sensibilidade são-nos dados objetos e só ela nos fornece intuições; mas é o entendimento que pensa esses objetos e é dele que provêm os conceitos." ${ }^{19}$ A intuição é sempre sensível ${ }^{20}$, afecção de nossa faculdade receptiva da sensibilidade, e nos dá assim o conteúdo da representação; em contraposição, o conceito é pura forma do objeto representado, construída a partir da espontaneidade do entendimento. Assim, a conjunção ou cooperação entre esses dois modos cognitivos circunscreve a totalidade da experiência humana finita.

Desse modo, entretanto, a unidade originária dessa disjunção, aquela raiz inescrutável, permanece de fato intacta. $O$ objetivo de Fichte, explicitamente declarado, é investigar essa fonte originária do saber. ${ }^{21} \mathrm{Em}$ certo sentido, o projeto do idealismo transcendental, se levado às suas últimas consequências, precisa explicitar inclusive a gênese de intuição e conceito, tomadas como as duas únicas formas possíveis de conhecimento, e deve realizar essa gênese de maneira absolutamente imanente à própria consciência. No entanto, mesmo Fichte, já em meados de sua XIII lição do segundo curso de 1804, confessa a dificuldade que tal explicação da unidade última do saber acarreta: "permanece ambíguo, se o pensamento se origina a partir dessa intuição, ou se a intuição se origina do pensamento, ou ainda se ambos não seriam apenas fenômenos de uma unidade oculta que os fundamenta." (WL 1804² GA II/8, 194/ FSW X, 189) A doutrina-da-ciência propõe-se a realizar a complicada (e talvez irrealizável) tarefa de autofundamentar o conhecimento, e assim fundamentá-lo de modo último.

Como consequência inevitável dessa tarefa, a discussão de Fichte sobre o sentido da dualidade entre entendimento e sensibilidade não pretende mais, como constava na investigação kantiana, explicitar o papel que ambas as faculdades tem no processo de construção do conhecimento científico. A revolução copernicana de Fichte consiste justamente em transformar os próprios modos de conhecimento da estrutura transcendental da razão em seus objetos de investigação. Em outras palavras, a discussão sobre a distinção entre intuição e conceito é na doutrina-da-ciência uma discussão sobre os modos imediato e mediato de saber, ou melhor dito, sobre a maneira como a imediatez intuitiva e a mediação conceitual podem determinar a 
autoconstrução do saber, que por sua vez não é senão a própria autoconstrução da consciência. "Nós refletimos assim não mais sobre o conteúdo, do qual muito bem poderíamos abdicar, mas sim sobre o procedimento; perguntamos consequentemente pela gênese". (WL $1804^{2}$ GA II/8, 78/FSW X, 129)

De fato, não só essa distinção entre conceito e intuição se dirige a outro foco epistêmico, como também é possível estabelecer uma segunda distinção, interna à própria noção de intuição. Por um lado, o termo intuição mantém na teoria de Fichte um aspecto de seu uso kantiano, a saber, o modo receptivo com que a intuição se relaciona a seu objeto. Evidentemente, conforme o exposto logo acima, esse "objeto" da intuição fichtiana não corresponde mais a um dado empírico captado pela sensibilidade, mas pode ser compreendido como um conceito determinado dado, ou ainda, um fato da consciência. Assim, a contraposição entre conceito e intuição, isto é, entre conceituar e intuir, ocorre justamente a partir dessa definição. 0 conceituar constrói "objetos" conceituais que são por sua vez captados pelo intuir da consciência.

Porém, o termo intuição parece indicar ainda outro significado mais profundo, e a meu ver essencial à tarefa de elucidação do próprio saber. Mesmo que Fichte não tenha em nenhum momento de toda sua obra delimitado um sentido estrito para esses termos distintos, o uso fichtiano preferencial de Intuition (Intuição) no lugar de Anschauung (intuição) $^{22}$, no contexto teórico da Doutrina-da-Ciência de 1804, sugere uma demarcação forte entre duas acepções para tal noção. Assim, em contraposição ao primeiro sentido destacado anteriormente, da intuição (Anschauung) como captação fática de um conceito, poder-se-ia considerar Intuição (Intuition) como referente a uma autocaptação, e nesse sentido como um termo equivalente à intuição intelectual do período de Jena. No entanto, é preciso observar aqui que ambos sentidos considerados estão agora desvinculados de qualquer relação com o conhecimento empírico, o que significa dizer que ambas as intuições são aqui, em certa medida, intuições "intelectuais". O critério de distinção entre essas duas acepções, portanto, diz respeito não mais à natureza do objeto da intuição, mas sim ao modo de realização dessa intuição. Para utilizar o vocabulário do próprio autor, mesmo que Fichte não empregue exatamente dessa forma, poderíamos denominar o primeiro sentido por 'intuição fática' e o segundo sentido por 'intuição genética'. Essa distinção é indicada, talvez de maneira não muito clara, na seguinte passagem do texto de Fichte:

"Acabei de tocar aqui, de passagem e aliud agendo, na seguinte diferença importantíssima, entre o mero visar fático (faktischer Ansicht), tal como nosso pensamento do em-si, e o intuicionar genético (genetischer Einsicht), tal como no construir-a-si-mesmo do em-si. De acordo com o testemunho de nossa consciência imediata, não podemos observar nosso pensamento enquanto pensar ${ }^{23}$, verbaliter, enquanto construção; nós apenas o vemos na medida em que ele é, ou deve ser, e ele já é ou deve ser na medida em que o vemos; ao contrário, vemos o em-si como sendo e construindo-se ao mesmo tempo, e vice-versa." (WL 1804² GA II/8, 196/FSW X, 191)

A bem dizer, a passagem supracitada não se refere especificamente a dois modos de intuição, mas esclarece aquela diferença no modo de captação através da contraposição entre pensamento e intuicionar. No entanto, a segunda parte do parágrafo em questão parece traduzir essa relação justamente a partir da diferença entre um ver fático do pensamento e um ver genético do mesmo. Em outras palavras, Fichte retoma aqui, a partir de outras expressões de linguagem, a mesma discussão do período de Jena sobre dois modos de consciência, isto é, sobre a distinção entre uma consciência intencional e uma consciência não-intencional ou pré-reflexiva. Neste caso, ao modo de relação 
objetiva da consciência intencional corresponde o "visar fático", enquanto que ao outro modo, relativo à consciência não-intencional, corresponde o "intuicionar genético".

Sendo assim, será preciso distinguir na estrutura da consciência, além dos dois modos de captação cognitiva mencionados, ao menos três instâncias ou "faculdades" de conhecimento. Se, por um lado, há uma contraposição entre conceito e intuição, e nesse sentido uma contraposição correspondente entre pensar e intuir, essa duplicidade cognitiva, por sua vez, deverá ser unificada a partir de uma intuição superior, isto é, a partir de um verdadeiro intuicionar (Einsicht), ou simplesmente, como indica Fichte claramente no seguinte trecho da primeira série de preleções de 1804, a partir da intuição intelectual:

"Esse ponto tornar-se-á completamente claro quando nos elevarmos até o intuicionar da conexão necessária entre a absoluta intelecção e o absoluto intuir em nós mesmos, e por isso nos elevarmos até a intuição intelectual, enquanto o verdadeiro ponto de vista interno da doutrina-da-ciência." (WL $1804^{1} \mathrm{GA}$ II $/ 7,131$ )

Entretanto, Fichte não pretende estabelecer essa unidade última do conhecimento, que unifica pensar e intuir, simplesmente como que por um passe de mágica, ou um "tiro de pistola", para usar a expressão de Hegel. A argumentação da Doutrina-da-Ciência de 1804 parte de uma análise crítica sobre a insuficiência de intuição e conceito como modos adequados de captação do saber enquanto saber. Somente através dessa crítica, que em certa medida é uma descrição do caráter fenomênico da própria consciência determinada, será talvez possível realizar, por via negativa, aquele estado-de-ação que corresponde à intuição intelectual, isto é, será possível estabelecer a identidade entre a consciência pura e o próprio saber.

A partir da XIII preleção de 1804, Fichte retoma a comparação entre as duas posições epistêmicas do realismo e do idealismo, para então fazer uma análise mais detalhada do seu resultado. Na medida em que o realismo superior pretende negar o idealismo a partir de uma intuição fática do em-si ou puro $\operatorname{ser}^{24}$, e, por outro lado, o idealismo superior nega a posição realista através de um conceituar fático do ser aí ${ }^{25}$, isto é, da consciência determinada, tal contraposição será interpretada também como contraposição entre intuição e conceito. Sem dúvida, trata-se de mostrar aqui que em ambos os casos, a unidade do saber não se estabelece justamente por causa da facticidade cognitiva unilateral que cada uma representa. Eis, portanto, como Fichte reapresenta a posição idealista:

"Para intuicionarmos o em-si, enquanto negando o Ver, deveríamos refletir energicamente sobre ele. Portanto, mesmo que não pudéssemos negar que ele constrói a si mesmo e com isto também à luz, tudo isso estava condicionado por nossa reflexão enérgica, e essa era, por conseguinte, o mais alto membro de todos. Isto é claramente, na medida em que se baseia faticamente em uma reflexão absoluta, Idealismo (...)". (WL $1804^{2}$ GA II/8, 32/FSW X, 188)

Em outras palavras, a tentativa de pensar o em-si, a objetividade absolutamente independente da construção do pensamento, falha inevitavelmente, pois o pensamento, em sua relação fática ou intencional com o objeto, não consegue se colocar na própria posição do em-si, isto é, não consegue ser ele próprio essa autoconstrução do que está sempre para além do pensar. Da mesma forma, a posição realista, na medida em que postula uma intuição fática do em-si, não possibilita uma apreensão determinada do mesmo, pois a determinidade do conceituar, isso que Fichte chama de "forma existencial externa", é absorvida pela pura gênese do em-si. É o que se pode depreender da seguinte passagem, um tanto obscura, do texto de Fichte: 
“Também no realismo a autoconstrução será pura e simplesmente intuicionada; mas ela será intuicionada, i.e., ela será inserida em um vivente em si mesmo, e esse vivente arrasta o intuicionar consigo, a mesma relação que já encontramos mais de uma vez naquela evidência estabelecida por nós como evidência genética; e isso cada um agora deve encontrar na intuição. Ainda que seguramente uma Intuição objetivadora também pareça oscilar sobre a gênese, ela será da mesma forma arrastada até a gênese e com a gênese. Parece estar sendo indicado nesse intuicionar, portanto, uma unificação da forma existencial externa com a interna, da facticidade com a gênese." (WL $1804^{2}$ GA II/8, 192/FSW X, 189)

Através desses exemplos é possível delimitar o seguinte: a contraposição entre uma intuição fática e um conceituar fático explicita uma tensão primordial inerente à tentativa de fundamentação última do saber. Para realizar essa fundamentação de maneira consistente, Fichte precisa explicar como se pode unificar o em-si e a consciência do em-si, ou simplesmente, ser e pensar, de modo que tal unificação seja imanente ao saber, e nesse sentido pressuponha a construção conceitual da consciência determinada, sem que com isso a verdade do em-si, dessa vitalidade absoluta que Fichte também denomina "pura luz", seja reduzida à própria consciência manifesta. Melhor dito, a fundamentação última do saber tem que indicar como é possível demonstrar, para usar uma expressão de Husserl, a transcendência dentro da própria imanência do saber. ${ }^{26}$

Devido a essa dificuldade central, entende-se por que a Doutrina-da-Ciência de 1804 precisa estabelecer uma distinção radical entre aquele idealismo absoluto que deveria deduzir tudo a partir do eu absoluto - imputado por todos os críticos de Fichte à sua teoria (WL $1804^{2}$ GA II/8, 200-2/FSW X, 193) - e o idealismo crítico-transcendental defendido pelo autor, que pretende estabelecer esse mesmo sujeito absoluto, isto é, a consciência, enquanto manifestação ou imagem ${ }^{27}$ de um fundamento incognoscível e verdadeiramente absoluto. Somente nesse sentido é possível compreender as objeções do próprio Fichte à teoria da consciência, objeções cujo conteúdo não implica uma assim denominada "despotenciação" do papel do eu no desenvolvimento tardio da doutrina-da-ciência ${ }^{28}$, mas sim denota uma compreensão mais aguda sobre o que pode ser determinado como limite do próprio conhecimento. Por isso Fichte pode afirmar o seguinte:

"de acordo com esse sistema idealista, a consciência seria um fato, e como a consciência é para ele o Absoluto, o Absoluto seria um fato. Mas a doutrina-daciência, desde o primeiro instante de seu surgimento, esclareceu que o proton pseudos dos sistemas anteriores seria partir de fatos, e postular nesses fatos $o$ Absoluto; ela tem por fundamento, como atestou, um estado-de-ação [Tathandlung], palavra muito alemã, a qual designa aquilo denominado nessas preleções pela palavra grega gênese, frequentemente melhor compreendida do que aquela outra." (WL $1804^{2}$ GA II/8, 202/FSW X, 194)

Só agora é possível delinear uma gênese da verdade a partir da própria consciência. $O$ caminho argumentativo ascendente da Doutrina-da-Ciência de 1804, também denominado por Fichte Wahrheitslehre (doutrina da verdade), faz uma espécie de demonstração apofática da verdade, na medida em que analisa as duas possibilidades epistêmicas de explicação da experiência humana, o realismo e o idealismo, para em seguida mostrar cada qual como unilateral e insuficiente, em relação ao objetivo de uma fundamentação última do conhecimento. Essa análise indica como erro fundamental de ambas as posições uma forma de relação epistêmica meramente fática, que não permite estabelecer a estrita autofundamentação do saber, pois dita facticidade gera um abismo inexplicável entre a manifestação do saber e seu fundamento, ou, como descreve mais 
adiante Fichte, produz uma projeção "per absolutum hiatum". (WL 1804² GA II/8, 218/ FSW X, 200)

O conceito manifesta o saber, mas não capta a essência do mesmo. A intuição é um modo de captação imediata, mas não permite a determinação do saber. A consciência, portanto, na medida em que só pode ser determinada por conceitos, manifesta o fenômeno do saber. A verdade desse fenômeno ou aparecer da consciência não é construída pela própria consciência, e assim poderá surgir apenas a partir da aniquilação do conceito.

"O fundamento da verdade enquanto verdade sem dúvida não reside na consciência, mas completamente na verdade ela mesma; portanto, tu deves sempre abstrair da verdade a consciência, pois essa não dita nada àquela. Em relação à verdade a consciência é apenas fenômeno externo, do qual tu jamais podes sair, e cujo fundamento também deve ser indicado para ti." (WL 1804² GA II/8, 204/FSW X, 195)

No entanto, mesmo que Fichte utilize explicitamente o termo Vernichtung, não se deve interpretar essa aniquilação do conceito em sentido literal, de acordo com a observação de Traub (1998, p. 103), pois a teoria tardia da doutrina-da-ciência quer justamente estabelecer um vínculo de figuração entre o saber absoluto e o próprio Absoluto, e isso significa dizer que a aniquilação do conceito face à verdade é muito mais uma relação negativa a determinar os limites do discurso do que uma simples eliminação de toda manifestação frente ao próprio Absoluto. Caso contrário, o saber não seria "imagem de", mas uma completa nulidade. Por conseguinte, o modo de saber fático da intuição e do conceito não é propriamente aniquilado, mas se auto-aniquila, isto é, será demonstrado como insuficiente. Eis o motivo pelo qual a investigação fichtiana, ainda que compartilhe da inspiração mística de Jacobi, não compartilha com este o método.

Esse também o motivo que leva Fichte a buscar um ponto de unificação absoluta do saber, isto é, a legítima unidade entre o ser e o pensar, a partir da intuição intelectual. Sem dúvida, para tanto será preciso abstrair dos efeitos da consciência que impedem uma captação intuitiva da própria verdade do saber. (WL $1804^{2}$ GA II/8, 218/FSW X, 199) Mas isso não significa necessariamente uma abstração da própria consciência. Seria então a consciência, enquanto intuição intelectual, aquilo que Fichte determinou por "pura luz"?

Assim, a metáfora da "pura luz" não corresponde à forma do conceito, e também não corresponde ao próprio saber absoluto, mas sim àquela intuição imediata, que é o procurado ponto intermédio e princípio da conexão entre o ser substancial inconcebível e o conceito que se anula nesse ser. ${ }^{29}$

\section{Sobre verdade e certeza}

"A primeira exigência imposta a vocês", anuncia Fichte aos ouvintes de sua XXIII preleção de 1804, "é conceber a certeza com rigor e em sua completa pureza. Não se trata da certeza de alguma coisa, como era o caso da conexão dos membros complementares, pois foi realizada precisamente a abstração disso; mas se trata da certeza pura e em-si, com total abstração da coisa." (WL $1804^{2}$ GA II/8, 344/FSW X, 271) Com essa intrigante formulação, inicia-se no desenvolvimento da argumentação fichtiana aquilo que poderíamos considerar o ponto crucial da epistemologia da doutrina-da-ciência. Fichte pretende investigar aqui a relação entre verdade e certeza, 
de modo a mostrar que a fundamentação última do conhecimento só poderá investigar o primeiro conceito a partir do segundo, isto é, a verdade incondicionada se torna indiretamente acessível apenas através de uma autofundamentação ou autocertificação da própria certeza, considerada no sentido estritamente puro acima aludido. Eis, portanto, o momento crítico de justificação (e consequente autojustificação) da teoria fichtiana.

Sem dúvida, em proporção direta à importância da discussão que ocorre nessa seção da obra, se apresenta aqui também um dos capítulos mais obscuros do curso de 1804. Fichte reúne em poucos parágrafos uma intrincada relação de conceitos-chave, os quais nem sempre são devidamente esclarecidos, ou muitas vezes assumem ad hoc o ônus de uma demonstração não realizada, ainda que talvez irrealizável. Sendo assim, como objetivo principal do presente trabalho, tentarei esclarecer alguns pontos da XXIII preleção que me parecem contribuir para a compreensão da teoria epistemológica fichtiana, mais especificamente no que concerne à discussão sobre a intuição intelectual e sua relação com os conceitos de verdade e certeza.

Para tanto, além de uma remissão direta e detalhada ao texto de Fichte, será necessário também fazer uma análise crítica da interpretação, específica sobre esse capítulo fundamental, apresentada na monografia de Ulrich Schlösser, Das Erfassen des Einleuchtens, um dos poucos trabalhos recentes que investiga a Doutrina-da-Ciência de 1804 a partir de um ponto de vista analiticamente rigoroso. Esse cotejo servirá para melhor avaliar em que medida a estratégia de Fichte para estabelecer uma fundamentação do saber tem ou não êxito, bem como se ela mantém ou não sua coerência interna.

41 Já na segunda preleção de 1804, Fichte indica de certo modo o caminho norteador de toda sua investigação, descrevendo, a partir dos conceitos de verdade e certeza, aquela unidade fundamental entre ser e pensar que a doutrina-da-ciência pretende estabelecer. Eis o trecho em questão: "todo ser põe um pensar ou uma consciência dele próprio; que portanto o ser seria
membro e primeira metade de uma disjunção, cuja outra seria o pensar; por isso, a
unidade não estaria nem em uma metade nem na outra, mas no vinculo absoluto de
ambas = puro saber em e para si, portanto saber de nada, ou, se a seguinte
expressão for mais fácil de recordar, deveria ser posto na verdade e certeza em e para
si, que não é certeza de alguma coisa, pois assim já estaria posta a disjunção entre
ser e saber." (WL $1804^{2} \mathrm{GA}$ II/8, 20/FSW X,99)

42 Aparece aqui mais uma vez o esforço do autor em determinar um conceito de verdade que não pressuponha qualquer forma de relação externa entre dois relata, o que em certo sentido é ao mesmo tempo uma crítica ao paradigma clássico da teoria da verdade por correspondência. Conforme visto anteriormente, essa dualidade epistêmica surge tanto no modo como a consciência intencional se relaciona com seu objeto, quanto na forma fática como conceito e intuição determinam certo conteúdo cognitivo. Nesse sentido, a unidade última do saber deve consistir em um espécie de verdade "nãoobjetal", e portanto, como indica o texto acima, se estabelece como "puro saber" ou "certeza em e para si".

43 Se, no entanto, a única possibilidade de realizar uma determinação de algo é através dessa contraposição dual, inerente a qualquer esclarecimento conceitual discursivo, de que maneira é possível determinar uma tal unidade ou verdade não-objetal que, justamente por isso, não pode ser determinada? Para resolver esse impasse filosófico aparentemente intransponível, Fichte adota uma estratégia sui generis: a partir de uma 
tentativa de determinação minimalista daquilo que o autor denomina "certeza pura", a doutrina-da-ciência pretende mostrar que existe um vínculo necessário entre dois níveis distintos do discurso, ou melhor dito, entre duas esferas da experiência cognitiva. $\mathrm{O}$ argumento fichtiano parte de uma descrição objetiva da certeza em direção à realização ou efetivação dessa certeza pela própria atividade do sujeito. Como último passo, depois de garantida a identidade entre a pura certeza e o próprio eu, realizar-seá uma breve investigação acerca da arquitetura interna desse saber originário.

Assim, o primeiro passo do argumento é indicado no texto de Fichte através de uma simples solicitação:

"Se agora lhes requisitasse para descreverem melhor essa pura certeza, de maneira mais precisa, como procederiam? Creio que de nenhum outro modo senão pensando a mesma como imperturbável permanecer e descansar no mesmo imutável uno; no mesmo, disse, portanto, em um inalterável quê ou qualidade. Assim, não podem descrever a pura certeza de outro modo, senão como pura imutabilidade, e a pura imutabilidade de nenhum outro modo, senão como uma permanente unidade do quê ou da qualidade." (WL $1804^{2} \mathrm{GA} \mathrm{II} / 8,346 / \mathrm{FSW}$ X, 272)

Essa descrição abstrata de uma primeira propriedade da certeza, a partir de uma qualidade ou quê imutável, ainda que não permita estabelecer uma definição precisa sobre o conceito em questão, ao menos revela um aspecto importante sobre a teoria do conhecimento de Fichte: não há uma certeza parcial, não se pode estar realmente certo sobre alguma coisa apenas temporariamente, ou sob certas condições. Certeza é um "imperturbável permanecer e descansar no mesmo", uma identidade absoluta consigo. A mesma ideia, sem dúvida recorrente em toda obra de Fichte, recebe uma descrição análoga, por exemplo, na Segunda Introdução à Doutrina-da-Ciência, quando o autor fala sobre a noção correlata de convicção. (cf. ZE, GA I/4, 264/FSW I, 513)

Como segundo passo, Fichte então retoma a mesma descrição anterior, fazendo agora uma análise do próprio procedimento de construção dessa descrição. Em uma passagem que apresenta notável similaridade com o argumento inicial da Doutrina-da-Ciência de 1801/2, a saber, aquele experimento que incita o leitor a construir um triângulo, Fichte pretende provocar uma espécie de transposição do ponto de vista de seu interlocutor, indicando uma passagem desde o conteúdo proposicional da certeza do quê imutável até o estado de consciência que permite reconhecer o sentido e a validade dessa proposição. Por isso diz o autor:

"Prestemos atenção, tal como sempre procedemos em questões similares, apenas em nossa maneira de proceder. Nós construímos um quê em geral, e o postulamos como imutável; e com isso a essência da certeza se manifestou para nós. Pergunto: se repetíssemos esse procedimento ao infinito, como manifestamente nos parece possível fazer, poderíamos alguma vez estabelecê-lo de um outro modo? A construção do quê é absolutamente imutável, e em todas suas infinitas repetições apenas é possível do único modo descrito, através da absoluta negação da mutabilidade: nós vemos a nós mesmos portanto também assim, tal como descrevemos a certeza, como persistindo imutáveis no mesmo quê uno da construção; nós somos aquilo que dizemos, e dizemos aquilo que somos." (WL 1804 GA II/8, 348/FSW X, 273)

Surge assim, neste ponto, um recurso argumentativo indispensável no tocante ao projeto de fundamentação proposto pela Doutrina-da-Ciência de 1804, e especialmente relevante para a presente discussão. A transição entre o estado imutável da certeza, instanciada em um abstrato quê, e o correspondente estado imutável da consciência que permite realizar uma tal descrição, essa identidade do dizer a certeza e do ser a 
própria certeza, representa uma tentativa de fusão das dimensões lógica e pragmática do discurso. Assim, a estratégia de Fichte consiste em estabelecer uma identidade entre o conceito formal de certeza, caracterizado como permanência do mesmo, e nossa identidade no postular desse conceito, isto é, a imutabilidade de nossa própria "experiência" da certeza. Como observa Schlösser, “(...) o pensamento da certeza só é válido porque ele se dá a partir da realização originária da certeza. Assim, não se deve conectar apenas a determinidade ao conceito de certeza, mas ainda esse conceito ao intuicionar real realizado." ${ }^{30}$

Em certa medida, essa identidade pragmático-conceitual que transfere o sentido da proposição à experiência ou ação do sujeito, isso que Schlösser denomina "tautologia pragmática" (Ibidem), não é senão uma transformação terminológica tardia daquela ideia fundamental contida no conceito de intuição intelectual, a saber, que só é possível conhecer tal intuição a partir de uma ação, mais ainda, através de uma pura ação, simplesmente realizando essa mesma intuição. Por isso, a unidade última do saber é a unidade de nossa própria construção desse saber, mas como nós mesmos somos uma unidade em autoconstrução, um eu que põe a si mesmo enquanto ponente, o saber se revela idêntico ao próprio eu. Como afirma Fichte, "nós mesmos, no que fazemos e exercemos, somos saber, pensamento, luz, ou como queiram denominar isso." (WL $1804^{2}$ GA II/8, 296/FSW X, 243)

Somente a partir dessa identidade entre diferentes níveis do discurso - a bem dizer sequer poderíamos falar aqui, no que se refere à atividade originária do eu, de um nível de "discurso" - se torna possível estabelecer o saber absoluto como um sistema autoreferente e efetivamente transparente a si mesmo. $O$ fechamento absoluto do sistema do saber, da mesma forma como afirmara Fichte ainda em 1797/8, só se dá através de uma ação do espírito: "teu pensar é para ti um agir." (VND GA I/4, 271/FSW I, 522) Caso contrário, não haja essa concordância entre as duas esferas em questão, o saber se mostra como algo condicionado ou parcial. Como afirma o autor na XIX preleção de 1804, "simplesmente em todo saber derivado, ou em todo fenômeno, há uma pura contradição entre o fazer e o dizer: propositio facto contraria". (WL $1804^{2}$ GA II/ $8,288 /$ FSW X, 238)

De fato, é também através dessa identidade que a teoria de Fichte pretende evitar o regresso ao infinito na cadeia de fundamentação do saber, causado pela estrutura dual da referência objetal da consciência. Se há um fundamento último de todo saber, ele deve ser uma instância que colige internamente, como sua própria essência, ser e saber. Sem dúvida, eis uma ideia crucial da filosofia de Fichte, mas que se revela como absolutamente incomunicável. A estrutura proposicional e predicativa do discurso simplesmente não consegue expressar essa espécie de unidade dual do puro saber, uma relação tão interna que parece não constituir propriamente uma relação. Por isso, Fichte precisa recorrer a uma linguagem metafórica, descrevendo essa instância última, por exemplo, como visão que se conhece enquanto visão, ou, para a usar a expressão da primeira série de preleções do inverno de 1804, uma luz que "não é, sem luzir em si mesma." (WL 1804', GA II/7, 218)

"De acordo com o intuicionar [Einsicht] gerado ontem por nós, que o Ver e a luz, e de fato sempre somente no Ver imediato ele próprio, jamais se encontram no Ver visto, fica claro que o primeiro termo absoluto reside naquilo que vivemos e exercemos; - de modo algum em algo objetivado que espera seu ser de um princípio, e que com isto por certo seria o é verdadeiramente morto em si mesmo." (WL $1804^{2}$ GA II/8, 288/FSW X, 258) ${ }^{31}$ 
51 Exatamente devido à referida clausura absoluta do saber, que descreve um segundo aspecto fundamental do conceito de certeza, surge uma dificuldade para a argumentação de Fichte. Por um lado, dita clausura se apresenta condição necessária e constitutiva desse saber, ou simplesmente do eu, como deixa bastante claro o seguinte trecho do texto fichtiano:

"Que a certeza está fundada em si mesma significa por sua vez que ela está fechada em si mesma de modo absoluto e imanente, e jamais pode sair de si: ela é em si mesma um eu; portanto, tal como a mesma prova sobre a forma do ser foi conduzida acima. Fica claro, assim, que a certeza exteriorizada e objetivada até agora estabelecida por nós não é a absoluta, segundo a forma, ainda que poderia muito bem o ser em conteúdo e essência. Fica claro, assim, que em nossa busca pelo Absoluto devemos abstrair disso, e procurar [a certeza absoluta] somente naquilo que se revela como imanente, como eu ou nós." (WL $1804^{2}$ GA II/8, 350/FSW X, 274)

Essa imanência absoluta, por outro lado, inscreve o saber em uma mônada completamente desprovida de janelas. Dito de outro modo, a certeza absolutamente "fechada em si mesma" postulada pela teoria de Fichte, de acordo com sua própria definição rigorosa, parece excluir qualquer possibilidade de acesso a sua própria manifestação. Existe aqui uma tensão fundamental entre o caráter intrínseco do ser do saber absoluto e seu caráter manifesto enquanto saber de si, isto é, uma tensão entre a essência e a aparência desse mesmo saber, denominados também por Fichte como "forma existencial externa" (emanente) e "forma existencial interna" (imanente). Mais uma vez, nos deparamos com o problema de estabelecer, dentro do idealismo transcendental, uma forma de transcendência imanente. Fichte descreve esse problema do seguinte modo:

"Primeiramente, a certeza absoluta, pura e simplesmente em si e por si, é = eu ou nós; absolutamente inacessível para nós ou para si mesma, o que é completamente o mesmo, fechada e oculta puramente em si. Pois fosse ela acessivel a si mesma, ou a nós - o que significa o mesmo -, então deveria ser fora de si mesma, o que é contraditório." (WL $1804^{2}$ GA II/8, 350/FSW X, 274)

Schlösser, ao diagnosticar esse elemento problemático ${ }^{32}$, tenta apontar uma solução a partir dos conceitos utilizados no próprio texto de Fichte, mesmo reconhecendo a obscuridade do trecho em questão. A linguagem de Fichte, nesse ponto de sua argumentação, parece abandonar o método analítico-regressivo característico da investigação transcendental e passa a postular conceitos dogmaticamente como princípios de explicação da estrutura imanente do saber, sem no entanto esclarecer de maneira precisa a origem e o significado de tais conceitos. Nesse sentido, conceitos como principiar (Principiiren), projetar (Projiziren) ou Intuir (Intuiren) deverão, segundo Fichte, cumprir a tarefa de justificar uma necessária manifestação interna do próprio saber, dessa certeza ou luz vivente que capta a si mesma a partir de um processo intuitivo. É o que se pode talvez depreender da seguinte e obscura passagem antes referida, traduzida abaixo na íntegra:

“Certeza ou luz é princípio imediatamente ${ }^{33}$ vivo, portanto, pura e absoluta unidade, justamente da luz, a qual de modo algum pode ser melhor descrita, mas apenas realizada; se quiséssemos descrevê-la, então deveríamos descrevê-la como unidade qualitativa, que aqui não nos serve de nada. Ela é para todo o sempre imediatamente um eu. Assim, naquilo que dizemos e na medida em que dizíamos o anterior, já estávamos nos contradizendo. Vida interior que tem que viver na vida imediata. Na medida em que dizíamos: ela é princípio vivo, já começávamos a descrevê-la, mas originariamente. O principiar é já seu efeito, mas seu efeito originário em nós mesmos, pois nós o somos. Ele próprio (ou nós, o que é 
equivalente), portanto, se descreve. Principiar, se pensarem isso de modo verdadeiramente preciso, é projetar; projetar de si imanente: e por certo, como isso reside absoluta e imediatamente na própria vida, não per hiatum ou objetivamente, mas [de modo] interno e essencial, per transubstantiationem, [o principiar] se faz projetar e Intuir. Observem: como isso reside na própria vida da luz, então absolutamente toda luz faz imediatamente a si mesma, assim ela é: portanto, ela é absolutamente Intuinte, e também [aquele que exerce] ${ }^{34}$ a doutrina-da-ciência não pode, em todo seu executar vivo, escapar dessa determinação, e nós também não lhe escapamos; ainda que, por uma lei que ainda não foi esclarecida, ele penetre no princípio, e para ele aquilo que de outro modo é absolutamente um ser se torna para ele um fazer a si. Esse completo intuicionar no principiar originário e real é coisa da doutrina-da-ciência." (WL $1804^{2}$ GA II/8, 352/FSW X, 276)

$54 \mathrm{Na}$ tentativa de extrair dessa intrincada rede conceitual um significado mais claro, Schlösser tenta delimitar algumas definições para os conceitos principais empregados no trecho supracitado. Assim, por exemplo, o autor indica o conceito do processo de principiar como correspondente à pura atividade (SCHLÖSSER, U. Op. cit, 2001, p. 144), define o conceito de projetar, enquanto atividade que se dá por meio da luz e resulta na própria luz, como determinação da "exteriorização interna" ou imanente da certeza (Ibidem, pp. 144-5), e descreve o conceito de Intuir enquanto instância que estabelece a referência epistêmica ao projetar (Ibidem, p. 145). Assim, a projeção não pode anteceder o processo cognitivo do intuir, ou ser pressuposta por ele, "se se quer evitar aporias na ordem sequencial, o sentido cognitivo já deve estar inserido no próprio processo de exteriorização." (Loc. cit.).

Portanto, a certeza se torna presente a si mesma, mais do que através de sua descrição conceitual, por uma autopresença imanente à sua própria realização - e aqui se pode notar claramente quão dificultoso é, para a teoria fichtiana, evitar definições circulares, bem como um vocabulário demasiadamente preso à ideia de causa sui ${ }^{35}$. A meu ver, essa dificuldade é justamente o principal motivo que leva Fichte a defender a tese de um conhecimento primordial e originário por intuição. O conceito de intuição - ou para ser mais estrito -, a intuição, (pois o conceito de intuição já representa a dicotomia que a própria intuição pretende resolver) é a única forma cognitiva que permite fundamentar o conhecimento enquanto tal a partir da imanência consciente:

“Agora, essa certeza se exterioriza, em si mesma = em nós, portanto, de fato imanente em toda exteriorização - de uma maneira que ainda não está clara para nós, por uma razão que logo será dada -, como intuição $0^{36}$ de um procedimento certo e absolutamente imutável." (WL $1804^{2}$ GA II/8, 350/FSW X, 274)

Não há qualquer dúvida sobre o papel central que essa ideia desempenha no desenvolvimento filosófico da doutrina-da-ciência de Fichte. Ainda que muitas vezes oculto sob as inúmeras reformulações terminológicas das também inúmeras versões da doutrina-da-ciência, a intuição pura ou intuição intelectual permanece como verdadeiro fundamento epistêmico da teoria fichtiana do saber absoluto. Em certo sentido, a própria obscuridade das explanações sobre a natureza desse princípio, e a explícita recusa fichtiana da necessidade de uma demonstração ostensiva do mesmo, mostram-se absolutamente consistentes com relação à estrutura interna de sua teoria.

Nesse sentido, devo aqui discordar em um ponto da interpretação de Schlösser. De acordo com o autor (2001, p. 147), Fichte parece defender uma espécie de fundamento do próprio intuir naquilo que ele denomina um “inteligir”. Primeiramente, é necessário observar que o uso fichtiano de Intelligieren é marcadamente inconsistente. No contexto da Doutrina-da-Ciência de 1804, se Fichte em alguns momentos parece referir-se ao 
inteligir como fundamento último da própria razão (cf. WL 1804. SW X, pp. 122, 310), em outras ocasiões ele é tomado como sinônimo de 'compreensão' (por exemplo, Ibidem, pp. 195 e 200), ou ainda a partir de sua contraposição à intuição fática, de certo modo, portanto, enquanto sinônimo de 'conceito' (cf. Ibidem, pp. 160 e 240).

Além disso, as passagens do texto utilizadas por Schlösser para comprovar sua interpretação contêm diferenças marcantes entre as duas versões do segundo curso de 1804, a edição de Immanuel H. Fichte (SW) e o texto assim denominado Copia ${ }^{37}$, diferenças justamente no ponto a ser provado. Referindo-se à XXIII preleção, Schlösser primeiramente afirma: "na presente seção do texto, Fichte não nos dá informações mais aprofundadas sobre a posição do inteligir." (2001, p. 147). Em seguida, o autor faz menção a uma passagem da última preleção (XXVIII) do curso de 1804. Devido à importância, para o argumento apresentado, do pequeno detalhe que diferencia as duas versões, reproduzo abaixo os dois trechos no original em alemão, ressaltando em negrito os pontos discordantes (em: WL 1804, pp. 308-9):

SW) In diesem sich schlechthin, in wirklicher Lebendigkeit und Existenz intuirend Machen besteht nun das [r]eine ${ }^{38}$ an sich klare und durchsichtige Licht (= Vernunft), erhaben über alle objektivirende Intuition, als selber ihr Grund, und füllt nun durchaus |den Hiatus zwischen Objekt und Subjekt, vernichtet daher beide.

Copia) NB: In diesem sich schlechthin, in wirklicher Lebendigkeit und Existenz intuirend Machen besteht nun das reine sonach klare und durchsichtige Intelligieren, erhoben über alle objektivirende Intuition, als selber ihr Grund, und füllt nun durchaus |den Hiatus zwischen Objekt und Subjekt, vernichtet daher beide. ${ }^{39}$

Assim, essa indicação textual demonstra, no mínimo, uma hesitação de Fichte sobre qual a melhor maneira de expressar o inexprimível fundamento de sua doutrina-daciência. Em última instância, a explicação do saber intuitivo só é possível por via negativa, pois toda explicação é necessariamente discursiva. Enquanto modo cognitivo, porém, a intuição se mostra como única possibilidade de justificar ou fundamentar de modo último o próprio conhecimento, pois sua certeza imediata, proveniente da gênese in actu que a consciência perfaz sobre si, é justamente o que permite à doutrina-daciência superar o Entzweiung da própria razão. Ao mesmo tempo, a superação dessa dicotomia torna a teoria de Fichte imune às objeções do Trilema de Münchhausen. Resta saber se essa mesma intuição, no que concerne sua segunda acepção, ao pretender intuir sua própria negação, não se encontra, por fim, na mesma situação daquele barão, como gracejou Mme. de Staël.

\section{NOTAS}

1. Desde o escrito programático Sobre o Conceito da Doutrina-da-Ciência, publicado pouco antes da Wissenschaftslehre de 1794, Fichte defende a concepção de uma verdade única e universal, que se traduz também na seguinte tese: a doutrina-da-ciência constitui o sistema único do saber, fundado em um único princípio auto-evidente, cuja certeza determina a certeza de todas outras proposições desse sistema, e a partir do qual outros princípios sub-determinados, que fundamentam as múltiplas ciências particulares, são gerados. (Cf. BWL, FSW I, 41ss, e 59ss). Vide também a nota seguinte. 
2. Mais abaixo, Fichte complementa: "assim como é certo que há apenas uma concordância possível entre o verdadeiramente vivo e um variegado qualquer, assim também é certo que a unidade do princípio é de fato verdadeiramente o uno; pois princípios distintos acarretariam distintos principiados, e com isto distintos mundos desconexos entre si; e assim não seria possível qualquer concordância sobre alguma coisa. Mas sendo apenas um princípio o correto e verdadeiro, então se segue que apenas uma filosofia é a verdadeira, aquela que faz desse princípio verdadeiro o seu, e todas outras exceto ela são necessariamente falsas." (WL1804² GA II/8, 10/FSW X, 94). Como regra geral, todas as traduções são minhas, exceto quando indicado o contrário.

3. Minha adoção do vocábulo 'intuicionar', variação de 'intuir', para traduzir Einsicht ou einsehen, termos centrais no texto fichtiano de 1804, decorre da inaptidão etimológica, a meu ver, do conceito de intelecção. Ao contrário de intueri/inspicere, correspondentes latinos ao einsehen, 'intelecção' provém do verbo intelligere, o qual por sua vez é uma síntese de inter + legere, denotando no sentido originário um coletar ou selecionar entre partes. Assim, 'intelecção' parece indicar uma compreensão por análise, ou por síntese de partes. Além disso, Fichte utiliza também o termo intelligieren, ainda que de modo um tanto ambíguo, na maior parte das vezes como contraposição a intuiren ou anschauen. 'Introspecção', por sua vez, devido a seu uso contemporâneo, parece induzir a uma conotação psicológica. A tradução inglesa tem evidentemente uma solução fácil: 'insight'. Interessante destacar aqui, ainda que discorde em parte da interpretação ali exposta, a nota que o tradutor francês, que traduz Einsicht por visão, apresenta como justificativa: "Einsicht: essa visão é uma forma da compreensão; malgrado seu caráter de imediatidade, Einsicht não se opõe à discursividade e à reflexão; ela é justamente o resultado dessas. Aqui se torna preciso que o sentido do discurso filosófico, dos conceitos representativos, em suma, das mediações é o de induzir em nós as condições do ato espiritual da compreensão, que é em si mesmo uma intuição ou uma visão intelectual imediata." (J. G. FICHTE, La Théorie de la Science - Exposé de 1804, trad. D. Julia, Paris: Aubier-Montaigne, 1967, p. 21, nota 7). Ainda assim, também por razão de ambiguidade, não se pode sem mais utilizar 'visão' ou 'ver' para essa tradução, pois Fichte continuamente empregará em sentido técnico o termo 'Sehen' e outras variantes do mesmo morfema. Uma possibilidade mais ousada seria a criação do neologismo 'introvisão'.

4. 0 mesmo problema aparece em GA II/8, 38/FSW X, 108.

5. Cf. dentre outros, GUEROULT, M. L'Évolution et la Structure de la Doctrine de la Science chez Fichte. Paris: Les Belles Lettres, 1930, p. 160; SCHÜSSLER, I. Die Auseinandersetzung von Idealismus und Realismus in Fichtes Wissenschaftslehre. Frankfurt a.M.: Klostermann, 1972, pp. 86-7. GROSOS, P. Système et subjectivité. Étude sur la signification et l'enjeu du concept de système: Fichte, Hegel, Schelling. Paris: Vrin, 1996, p. 91; BRITO, E. J. G. Fichte et la Transformation du Christianisme. Leuven: Peeters, 2004, p. 221; Em contraposição a isso, veja-se por exemplo como continua imediatamente o parágrafo do texto de Fichte citado mais acima: "saber em si mesmo, e, portanto, saber completamente sem objeto, pois de outro modo não seria um saber em si mas requereria objetividade para o seu ser". Loc. cit.

6. Por isso Fichte, na continuação do texto, faz a seguinte observação: "Depois que se ouviu dizer que a WL teria se apresentado como idealismo, então se concluiu que ela teria colocado o Absoluto no que mais acima se denominou pensamento ou consciência, o qual se contrapõe ao ser como sua outra metade, e que portanto não pode de modo algum ser o Absoluto, como tampouco o pode ser seu contrário." (WL1804² GA II/8, 16/FSW X, 96)

7. A expressão se refere aqui à tradução de 'Ur=Teilung', uma análise metafórica do conceito de juízo feita por Hölderlin no seu fragmento Urteil und Sein. Assim transcorre o texto: "juízo é no sentido mais alto e rigoroso a separação original do objeto e do sujeito unidos na intuição intelectual, aquela partição tão somente pela qual objeto e sujeito se tornam possíveis, a partição 
original". (Tradução de Joãozinho Beckenkamp) In: BECKENKAMP, J. Entre Kant e Hegel. Porto Alegre: EDIPUCRS, 2004, p. 106.

8. 'A' se refere aqui não ao próprio Absoluto, mas ao saber absoluto.

9. Fichte indica essa iteração pelo esquema "W - DS DS DS etc.", onde W abrevia Wissen e DS, Denken e Sein.

10. Nesse sentido, a análise de Fichte se assemelha ao percurso da Fenomenologia hegeliana. Cf. também uma análise crítica dessa relação em SIEP, L. Hegels Fichtekritik und die Wissenschaftslehre von 1804. Freiburg/Munich: Karl Alber, 1970, pp. 102-3.

11. Fichte enumera outras contraposições equivalentes: “ 0 e B". Zero, compreendido aqui como ser, o em-si, inconcebível; B como conceito (Begriff). Além disso, Fichte fala em "forma existencial interna e externa"; ou ainda, de acordo com o vocabulário da primeira WL de 1804, "essência e existência".

12. Cf. Metafísica $1006^{\mathrm{a}} 12-15$.

13. Fichte também utiliza o termo "Durcheinander".

14. SCHÜSSLER, I. Die Auseinandersetzung von Idealismus und Realismus in Fichtes Wissenschaftslehre, Frankfurt a. M.: V. Klostermann, 1972, p. 92.

15. STOLZENBERG, J. Fichtes Deduktionen des Ich 1804 und 1794. Fichte-Studien, Amsterdam, v. 30, p. 1-13, 2006, p. 3.

16. STOLZENBERG, Loc. cit.

17. Ou como diz o alemão suábio do autor, para usar a expressão de Hegel, "onde todas as vacas são pretas".

18. "O eu põe a si mesmo e é, em virtude desse mero pôr-se por si mesmo; e vice-versa: o eu é, e, em virtude de seu mero ser, põe seu ser." (GWL, GA I/2, 259/FSW I, 96); ou ainda: "o eu só é na medida em que é consciente de si”. (GWL, GA I/2, 260/FSW I, 97) - traduções de Rubens R. Torres Filho.

19. $\mathrm{KrV}$ B 33.

20. Deixarei de lado a discussão sobre a problemática tese kantiana das intuições puras: entendase por problemático aqui não o postular de formas puras da sensibilidade, enquanto condições de possibilidade de toda apreensão sensível, mas a apreensão das próprias intuições puras. Se a intuição pura, como afirma Kant de modo um tanto lacônico, "se verifica a priori no espírito" (B 35), ela deve ser intuída ou pensada? Ou seria ela apenas o produto de uma máxima abstração, tal como sugere a argumentação do início da Estética Transcendental?

21. "Para caracterizar agora a WL nesse ponto histórico, desde o qual também partiu minha especulação, completamente independente de Kant: a essência [da WL] consiste justamente no escrutínio da raiz, para Kant inescrutável, na qual o mundo sensível e o inteligível se concatenam, logo, na derivação real e conceitual de ambos os mundos a partir de um único princípio." (WL $1804^{2}$ GA II/8, 32/FSW X, 104)

22. Talvez esse seja também o motivo que leva Fichte a substituir, nesse segundo curso de 1804, a expressão 'intuição intelectual' (intellektuelle Anschauung) por termos como o Ver (das Sehen), o intuicionar (Einsicht), o evidenciar (Einleuchten), ou ainda o Intuir (Intuiren).

23. SW: Denken ao invés de denken.

24. Fichte equipara o realismo também a uma "gênese da vida" cf. WL $1804^{2}$ GA II/8, 190/FSW X, 187.

25. Ou também, de acordo com Fichte, "gênese do conceito". Cf. Ibidem.

26. "No coração da adesão fichtiana ao projeto da razão, se descobre uma idéia difícil de exprimir, mas muito profunda: a ultrapassagem dos primeiros movimentos da filosofia não é uma operação que visa subir uma escada, mas muito mais procurar sempre mais precisamente a transcendência no coração da imanência." PHILONENKO, A. L'Oeuvre de Fichte: A la Recherche de la Vérité. Paris: Vrin, 1984, p. 62. 
27. Como afirma Fichte, “esse idealismo, enquanto válido em si mesmo, é refutado: apesar disso, nada impede que ele venha a existir novamente como fenômeno, e provavelmente como fundamento originário de todo fenômeno." (WL $1804^{2}$ GA II/8, 202/FSW X, 194)

28. Cf. sobre isso STOLZENBERG, op. cit., 2006, p. 1.

29. STOLZENBERG, J. Die Grenzen des Wissens. Zu Fichtes Theorie der Selbstvernichtung des Wissens in der späten Wissenschaftslehre. In: ZÖLLER, G. (Ed.) Cambridge Companion to Fichte. Cambridge: Cambridge University, 2009, p. 14 (paginação do texto original em alemão cedido pelo autor, cuja versão em inglês se encontra no prelo).

30. SCHLÖSSER, U. Das Erfassen des Einleuchtens. Fichtes Wissenschaftslehre von 1804 als Kritik an der Annahme entzogener Voraussetzungen unseres Wissens und als Philosophie des Gewißseins. Berlin: Philo Verlag, 2001, p. 142.

31. Ou ainda, na preleção anterior: "Pergunto: saber, o que é, pois, o saber? Fá-lo, então justamente o fazes; o saber em sua absolutidade qualitativa não podes novamente saber; pois se o soubesses, e justamente agora o indicasses, então o Absoluto mais uma vez não estaria no saber sobre o qual sabes, mas em teu saber desse fato". (WL $1804^{2}$ GA II/8, 288/FSW X, 249)

32. SCHLÖSSER, U. Op. Cit., 2001, p. 143ss.

33. Aqui a edição SW traz, de modo equivocado, mittelbar (mediatamente).

34. Conforme correção da edição Meiner.

35. Esse problema foi analisado em GLOY, K. Selbstbewußtsein als Prinzip des neuzeitlichen Selbstverständnisses. Seine Grundstruktur und seine Schwierigkeiten. Fichte-Studien, Amsterdam, v. 1, p. 41-72, 1990, pp. 61-2.

36. Na Doutrina-da-Ciência de 1810, Fichte é bem explícito sobre esse ponto: "Portanto - deve estar presente para o eu uma intuição imediata de seu estado originário, com a qual ele compara seu estado presente de reflexão (...). Uma intuição, disse eu, não um conceito. - Quisesse o eu refletir sobre sua reflexão como um fato, e como modificação do puro e simples estado de reflexibilidade, então isto mesmo seria considerado como fundamento, colocado como princípio: e aí estaria um pensamento e no seu fundamento um conceito. Aqui não se dá o mesmo. Na reflexão ele se consome: - nenhuma modificação, ele simplesmente põe seu estado originário; imediatamente, sem mediação de uma proposição fundamental: expressão imediata do ser do saber. Portanto, intuição. Contudo, permanece para fora sobretudo a visibilidade, pois aquilo que é visto primeiro, é o próprio Ver: no Ver absoluto não há, porém, nada visível; portanto uma intuição intelectual". FICHTE, J. G. Die späten wissenschaftlichen Vorlesungen. v. 1. Stuttgart-Bad Cannstatt: FrommannHolzboog, 2000-, p. 105.

37. Manuscrito encontrado na biblioteca da Universidade de Halle, no começo desse século. Devido a sua extrema similaridade com a versão publicada por I.H. Fichte - cujo manuscrito original se perdeu -, incluindo particularidades da pontuação peculiar de Fichte, R. Lauth afirma que se trata de uma legítima cópia do mesmo. (conforme indicado na introdução do editor da edição Meiner das lições de 1804).

38. Editado por Immanuel H. Fichte.

39. Um outro trecho citado por Schlösser como justificativa (cf. 2001, p. 147), esse presente na XXIII preleção, apresenta também diferenças consideráveis (em: WL 1804. SW X, p. 275):

SW: "wie es ist, ist es projicirend, zuvörderst sich selber innerlich und qualitative, noch durchaus nicht objektive genommen; also - sich zum formalen Intuiren machend, unmittelbar durch das innere lebendige Principsein, als intelligirend, und intuirend, schlechthin in Einem Schlage, aber das Letztere in der That und Wahrheit zufolge des Erstern".

Copia: "wie es ist, ist es projicirend, zuvörderst sich selber innerlich und qualitative, noch durchaus nicht objektive genommen; also - sich zum_?_ Intuiren machend, unmittelbar durch das innere lebendige Principsein, also intelligirend und intuirend, schlechthin in Einem, aber das Letztere in der That und Wahrheit zufolge des Ersten".

Obs: o ponto de interrogação refere-se a um espaço deixado em branco no manuscrito. 


\section{RESUMOS}

In the following article, my intention is to point out some aspects of the way in which Fichte describes the general structure of reason in the Wissenschaftslehre 1804. In this regard, I will proceed with an analysis of three fundamental theses on the concept of truth, trying to indicate with it the necessary relation that interconnects the concept of truth with such concepts as unity, self-consciousness and certainty. I hope to show that the project of an absolute grounding of knowledge through intellectual intuition was not at all abandoned by Fichte's late work, but deepened in its most genuine sense.

\section{ÍNDICE}

Keywords: idealism, realism, doctrine of knowledge 1804, intellectual intuition

\section{AUTOR}

\section{THIAGO SANTORO}

Goiânia 